\title{
Susceptibility of Candida glabrata biofilms to echinocandins: alterations in the matrix composition
}

\author{
Célia F. Rodrigues (D), Maria Elisa Rodrigues (iD) and Mariana Henriques (iD) \\ CEB, Centre of Biological Engineering, LIBRO - Laboratório de Investigação em Biofilmes Rosário Oliveira, University of Minho, Braga, Portugal
}

\begin{abstract}
Candidiases are the most recurrent fungal infections, especially among immunosuppressed patients. Although Candida albicans is still the most widespread isolated species, non-Candida albicans Candida species have been increasing. The goal of this work was to determine the susceptibility of C. glabrata biofilms to echinocandins and to evaluate their effect on the biofilm matrix composition, comparing the results with other Candida species. Drug susceptibilities were assessed through the determination of minimum inhibitory concentration (MIC), minimum fungicidal concentration (MFC) and minimum biofilm eradication concentration (MBEC) of caspofungin (Csf) and micafugin (Mcf). The $\beta-1,3$ glucans content of the matrices was assessed after contact with the drugs. The data suggest that, generally, after contact with echinocandins, the concentration of $\beta-1,3$ glucans increased. These adjustments in the matrix composition of C. glabrata biofilms and the chemical differences between Csf and Mcf, seem responsible and may determine the effectivity of the drug responses.
\end{abstract}

ARTICLE HISTORY

Received 9 January 2018

Accepted 28 April 2018

\section{KEYWORDS}

Candida glabrata; echinocandin; biofilm; matrix; antifungal drug; resistance

\section{Introduction}

Infections caused by members of the genus Candida (candidiasis) have been increasing in recent decades and becoming more difficult to eradicate. There are about 15 different Candida species that cause infections in humans, and Candida glabrata is one of the most common (Pappas 2006; Pappas et al. 2015). Candidiasis generally occurs due to the unbalanced use of immunosuppressive drugs, broad spectrum antibiotics and the widespread use of indwelling medical devices, but also to the growth of immunogenic diseases, the upsurge of endocrine disorders, and the ageing and the increase in the patient population (Douglas 2003; Li et al. 2007; Garcia-Cuesta et al. 2014; Silva et al. 2017). Each Candida species has distinctive virulence factors, antifungal susceptibilities, and defined epidemiologies (Pappas et al. 2015). The aptitude of these organisms to form biofilms is a specific virulence feature which allows tissue attachment following infection of the host (McCall and Edgerton 2017). Biofilms are communities of microorganisms embedded in an extracellular matrix (Costerton et al. 1995; Donlan and Costerton 2002), which confers significant resistance to antifungal therapy and intense host immune responses (Fonseca et al. 2014; Rodrigues et al. 2014). This matrix is composed of exopolymeric compounds secreted by sessile cells, with all providing protection against environmental challenges (Pierce et al. 2017). Infections caused by biofilms are complicated due to inducible gene networks encoding different proteins that confer tolerance or resistance to many of the available antifungal drugs (Ramage et al. 2012).

Chemically, echinocandins are cyclic lipo-hexapeptides with modified N-linked acyl lipid side chains (Chang et al. 2017), biosynthesised by diverse members of the Ascomycota (fungi) on non-ribosomal peptide synthase complexes (Emri et al. 2013). The first echinocandin with antimycotic activity was discovered in the 1970s, and since, over 20 natural echinocandins have been isolated (Emri et al. 2013). By disturbing fungal cell wall synthesis through a non-competitive inhibition of $\beta$-1,3-glucan synthesis, these drugs weaken the cell wall, break down the cellular integrity and, finally, induce cell lysis (Debono and Gordee 1994; Perlin et al. 2007). Due to this mechanism of action the echinocandins (which include anidulafungin, caspofungin and micafungin) are generally well tolerated, avoiding the overlapping toxicities and drug-drug interactions with mammalian cells which are observed with the azoles and the polyenes (Wiederhold and Lewis 2003; Wiederhold et al. 2007; Chang et al. 2017). The high clinical efficacy in the non-neutropenic 
patient population, in patients with moderate to severe illness, and in patients with pre-azole exposure (Pappas et al. 2015; Perlin 2015b), resulted in echinocandins being recommended as the first-line antifungal agents to treat invasive candidiasis, especially Candida glabrata, due to its innate high azole resistance (Perlin 2007; Pappas et al. 2015). Although these antifungal drugs are active against most important Candida species, in which they display in vitro fungicidal activity (Barchiesi et al. 2005), in critically ill patients it is recognised that the achievement of their pharmacodynamic and pharmacokinetic targets show a large inter-individual variability (Chang et al. 2017). In Europe, micafungin (Mcf) is approved for use in paediatric patients of any age including neonates, while caspofungin (Csf) is approved for use in paediatric patients $\geq 1$ year old, since there are insufficient data regarding its use in those $<1$ year old (Tragiannidis et al. 2012; Viscoli et al. 2014). The use of Csf and Mcf is limited by the necessity for a once-daily intravenous dosage regimen, lack of an oral formulation and a limited spectrum (Barchiesi et al. 2005; Pappas et al. 2015; McCarty and Pappas 2016), but both echinocandins still show very good in vitro activity against clinically relevant isolates of Candida species (Pappas et al. 2007; Spreghini et al. 2012; Kohno et al. 2013; Perlin 2015a; Chapman et al. 2017). In trials involving adult and paediatric patients with invasive and oesophageal candidiasis, Mcf has been shown to be non-inferior to intravenous Csf, intravenous fluconazole or liposomal amphotericin B. The tolerability profile of Csf and Mcf are, in general, similar to fluconazole and are better tolerated than liposomal amphotericin B or oral itraconazole (Scott 2012).

The biofilm matrices of Candida species have a strong net of exopolymers, providing protection against physical and chemical environmental attack, such as by drugs. These polymers make it difficult for drugs to diffuse into the biofilm cells, which make the biofilms recalcitrant to antifungals (Al-Fattani and Douglas 2004; Rodrigues, Gonçalves et al. 2017; Dominguez et al. 2018). Hence, the goal of this work was to evaluate seven C. glabrata isolates, by comparison with C. albicans, C. parapsilosis and $C$. tropicalis, regarding their susceptibility in the planktonic and biofilm form to Csf and Mcf, and the biochemical variations induced in the composition of the matrices after the drug exposure, in order to relate these matrix variations with drug effectiveness.

\section{Material and methods}

\section{Organisms}

A total of 10 strains were used in the course of this study. Six clinical isolates of C. glabrata from Hospital Escala Braga in Portugal were recovered from different sites: oral cavity (C. glabrata AE2 and D1), urinary tract (C. glabrata 562123 and 513100), vaginal tract (C. glabrata 534784 and 585626); four reference strains were from the American Type Culture Collection (C. glabrata ATCC2001, C. albicans SC5314 (ATCCMYA2876), C. parapsilosis ATCC22019 and C. tropicalis ATCC750). The identity of all isolates was confirmed using CHROMagar Candida (CHROMagar, Paris, France) and by PCR-based sequencing using specific primers (ITS1 and ITS4) against the 5.8 s subunit gene reference. Genomic DNA was extracted following previously described procedures (Williams et al. 1995). The PCR products were sequenced using the ABIPRISM Big Dye terminator cycle sequencing kit (Perkin Elmer, Applied Biosystems, Warrington, UK).

\section{Growth conditions}

For each experiment, strains were subcultured on Sabouraud dextrose agar (SDA) (Merck, Darmstadt, Germany) for $24 \mathrm{~h}$ at $37^{\circ} \mathrm{C}$. Cells were then inoculated in Sabouraud dextrose broth (SDB) (Merck) and incubated for $18 \mathrm{~h}$ at $37^{\circ} \mathrm{C}$, under agitation at $120 \mathrm{rpm}$. After incubation, the cells were harvested by centrifugation, $3,000 \mathrm{~g}$ for $10 \mathrm{~min}$, at $4^{\circ} \mathrm{C}$ and washed twice with phosphate buffer saline (PBS, $0.1 \mathrm{M}, \mathrm{pH}=7.5 ; \mathrm{NaCl} 0.8 \%, \mathrm{KCl} 0.02 \%$, $\left.\mathrm{K}_{2} \mathrm{HPO}_{4} 0.02 \%, \mathrm{NaHPO}_{4} .12 \mathrm{H}_{2} \mathrm{O} 0.285 \%\right)$. Pellets were then suspended in RPMI-1640 ( $\mathrm{pH}=7$, Sigma-Aldrich, St Louis, MO, USA) and the cellular density was adjusted to $1 \times 10^{5}$ cells $\mathrm{ml}^{-1}$, using a Neubauer counting chamber.

\section{Antifungal drugs}

Csf and Mcf were kindly provided by MSD ${ }^{\circ}$ and Astellas , respectively. Aliquots of 5,000 $\mathrm{mg} \mathrm{l}^{-1}$ were prepared using dimethyl-sulfoxide (DMSO). The final concentrations used were prepared with RPMI-1640 (Sigma-Aldrich) for both drugs.

\section{Antifungal susceptibility tests}

All the antifungal susceptibility tests were performed using the microdilution method, in accordance to the European Committee on Antimicrobial Susceptibility Testing (EUCAST) guidelines (EUCAST [date unknown]; Arendrup et al. 2008).

\section{Minimum inhibitory concentrations (MICs)}

The inoculum was prepared by suspending five distinct colonies, $\geq 1 \mathrm{~mm}$ diameter from $24 \mathrm{~h}$ cultures, in at least $3 \mathrm{ml}$ of sterile distilled water. Then, the inoculum was suspended by vigorous shaking on a vortex mixer for 15 $\mathrm{s}$ and the cell density was adjusted to the density of a 0.5 McFarland standard and adding sterile distilled water as 
required, giving a yeast suspension of $1-5 \times 10^{6} \mathrm{CFU} \mathrm{ml}{ }^{-1}$ (colony forming units). A working suspension was prepared by a dilution of the standardised suspension in sterile distilled water to yield $1-5 \times 10^{5} \mathrm{CFU} \mathrm{ml}^{-1}$. The 96 -well plate was prepared with $100 \mu \mathrm{l}$ of cell suspension and $100 \mu \mathrm{l}$ of each antifungal agent (Csf: 0.001 to $0.075 \mathrm{mg} \mathrm{l}^{-1}$; Mcf: 0.002 to $0.2 \mathrm{mg} \mathrm{l}^{-1}-2 \mathrm{x}$ concentrated) and incubated at $37^{\circ} \mathrm{C}$, during $18-48 \mathrm{~h}$. Controls without antifungal agents were also performed (positive control: working solution of cells and RPMI-1640; negative control: sterile distilled water and RPMI-1640). Finally, the results were determined spectrophotometrically at $530 \mathrm{~nm}$ and the MIC was considered to be the value that inhibited 50\%, compared to the controls (according to EUCAST guidelines).

\section{Minimum fungicidal concentration (MFC)}

In addition to the previous step, $20 \mu \mathrm{l}$ of each cell suspension treated with Csf and Mcf were recovered to a new well and serial decimal dilutions in PBS were plated onto SDA. Agar plates were incubated for $24 \mathrm{~h}$ at $37^{\circ} \mathrm{C}$, and the total number of CFUs was determined. The results were presented as $\log _{10}$ CFU per unit area $\left(\log _{10} \mathrm{CFU} \mathrm{cm} \mathrm{cm}^{-2}\right)$ (Rodrigues and Henriques 2017).

\section{Minimum biofilm eradication concentration (MBEC)}

Standardised cell suspensions $(200 \mu \mathrm{l})$ were placed into selected wells of 96-well polystyrene microtitre plates (Orange Scientific, Braine-l'Alleud, Belgium). RPMI-1640 was used without cells, but without antifungal agent, as a negative control. As positive control, cell suspensions were tested with RPMI-1640, without the antifungal agent. At $24 \mathrm{~h}, 100 \mu \mathrm{l}$ of RPMI-1640 were removed and an equal volume of fresh RPMI-1640 plus the respective antifungal concentration was added (Csf: 0.5 to $3 \mathrm{mg} \mathrm{l}^{-1}$; Mcf: 3 to $17 \mathrm{mg} \mathrm{l}^{-1} ; 2 \times$ concentrated). The plates were incubated at $37^{\circ} \mathrm{C}$ for more $24 \mathrm{~h}$, a total of $48 \mathrm{~h}$, at $120 \mathrm{rpm}$. The number of cultivable cells on biofilms was determined by the enumeration of CFUs. For that, after the period of biofilm formation, all medium was aspired and the biofilms washed once with $200 \mu \mathrm{l}$ of PBS to remove non-adherent cells. Then, biofilms were scraped from the wells and the suspensions were vigorously vortexed for $2 \mathrm{~min}$ to disaggregate cells from the matrix. Serial decimal dilutions in PBS were plated on SDA and incubated for $24 \mathrm{~h}$ at $37^{\circ} \mathrm{C}$. The results were presented as total CFUs per unit area $\left(\log _{10} \mathrm{CFU} \mathrm{cm}{ }^{-2}\right.$ ) (Rodrigues, Gonçalves et al. 2017).

\section{Biofilm analysis}

Biofilm total biomass quantification - crystal violet staining

Total biofilm biomass was quantified by crystal violet (CV) staining in 96-well plates (Rodrigues and Henriques
2017). As described previously, after biofilm formation for a total of $48 \mathrm{~h}$, the medium was aspirated and non-adherent cells removed by washing the biofilms with PBS. Then, biofilms were fixed with $200 \mu \mathrm{l}$ of methanol, which was removed after $15 \mathrm{~min}$ of contact. The microtitre plates were allowed to dry at room temperature, and $200 \mu$ lof $\mathrm{CV}\left(1 \% \mathrm{v} \mathrm{v} \mathrm{v}^{-1}\right)$ were added to each well and incubated for $5 \mathrm{~min}$. The wells were then gently washed twice with sterile, ultra-pure water and $200 \mu \mathrm{l}$ of acetic acid (33\% $\mathrm{v} \mathrm{v}^{-1}$ ) were added to release and dissolve the stain. The absorbance of the obtained solution was read in triplicate in a microtitre plate reader (Bio-Tek Synergy HT, Izasa, Lisbon, Portugal) at $570 \mathrm{~nm}$. The results were presented as absorbance per unit area $\left(\mathrm{Abs} \mathrm{cm}^{-2}\right)$.

\section{Biofilm structure visualisation}

In order to examine the structure of biofilms, after biofilm formation in the presence or absence of both drugs, they were observed by scanning electron microscopy (SEM). For that, biofilms formed as described above were dehydrated with ethanol (using 70\% ethanol for $10 \mathrm{~min}$, 95\% ethanol for $10 \mathrm{~min}$ and $100 \%$ ethanol for $20 \mathrm{~min}$ ) and air dried for $20 \mathrm{~min}$. Samples were kept in a desiccator until further analysis. Prior to observation, the base of the wells was mounted onto aluminium stubs, sputter coated with gold and observed with an S-360 scanning electron microscope (Leo, Cambridge, MA, USA) (Rodrigues and Henriques 2017).

\section{Biofilm matrix composition evaluation}

Extraction method: biofilms were formed in 24-well polystyrene microtitre plates (Orange Scientific) (Rodrigues, Gonçalves et al. 2017). For this, 1,000 $\mu \mathrm{l}$ of yeast cell sus-

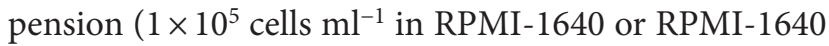
with Csf and $\mathrm{Mcf}$ at concentrations corresponding to the MBEC of each species/strain) were added to each well and the biofilms were treated as described previously (Rodrigues, Gonçalves et al. 2017). After 24 h, $500 \mu \mathrm{l}$ of RPMI-1640 medium were removed and an equal volume of fresh RPMI-1640 with or without the antifungal agents was added. After another $24 \mathrm{~h}$, the biofilms were scraped from the 24-well plates, resuspended in ultra-pure water, sonicated (Ultrasonic Processor, Cole-Parmer, Vernon Hills, IL, USA) for $30 \mathrm{~s}$ at $30 \mathrm{~W}$, and then the suspension vortexed for $2 \mathrm{~min}$. The suspension was centrifuged at $5,000 \mathrm{~g}$ for $5 \mathrm{~min}$ at $4^{\circ} \mathrm{C}$. The supernatant (matrix) was filtered through a $0.2 \mu \mathrm{m}$ nitrocellulose filter and dried at $37^{\circ} \mathrm{C}$ until a constant dry biofilm weight was reached. The pellets (sessile yeast cells) were discarded.

$\beta-1,3$ glucan concentration determination: $\beta-1,3$ glucan concentrations were determined using Glucatell kit (Cape $\mathrm{Cod}^{\circ}$, East Falmouth, MA, USA). The values were normalised per pg $\mu \mathrm{g}^{-1}$ of $\beta-1,3$ glucans/total polysaccharide 
content (evaluated by the phenol-sulfuric procedure using glucose as standard (DuBois et al. 1956).

\section{Statistical analysis}

All experiments were repeated three times in at least three independent assays. The results were compared using oneway and two-way ANOVA, Tukey's and Dunnett's multiple comparisons test, using GraphPad Prism 7 software (San Diego, CA, USA). All tests were performed with a confidence level of $95 \%$.

\section{Results}

\section{Planktonic and biofilm susceptibility to Csf and Mcf}

Table 1 shows the MIC, MFC and MBEC determined for all the strains used in this study. The values were species/ strain dependent, but, in general, MFC and MBEC of Mcf were higher than those from Csf. This was especially noticeable for the concentration needed to eradicate the biofilm (MBEC), which was sometimes 5-6 times higher than the MFC. Mostly, all C. glabrata strains were demonstrated to have biofilm resistance profiles similar to the other Candida species.

\section{Biofilm reduction capacity of Csf and Mcf}

$\mathrm{CV}$ staining was used to evaluate the biomass reduction in the Candida biofilms, after $24 \mathrm{~h}$ contact with Csf or Mcf (Table 2). Although both agents showed a good capacity in reducing the biomass, Csf had a higher capacity than Mcf. Four of the seven C. glabrata strains (585626, 534784, D1 and ATCC2001) had the lowest percentage biomass reduction for Csf and $\mathrm{Mcf}$, indicating a more tolerant profile of this species, comparing to the other species of Candida. On the other hand, C. albicans SC5314 ( $p<$ 0.001 for Csf and Mcf) was demonstrated to have the most marked biomass reductions.

\section{Biofilm structure}

SEM images (Figure 1A and B) confirmed that all Candida strains had a good capacity for biofilm production, especially C. glabrata AE2, C. glabrata D1 (biofilms formed in a long continuous carpet (Hawser and Douglas 1995; Fonseca et al. 2014; Rodrigues and Henriques 2017), C. albicans SC5314 (biofilm presenting high hyphal quantity and entanglement (Uppuluri et al. 2010; Rodrigues and Henriques 2017) and C. parapsilosis ATCC22019 (continuous biofilm carpet with clumped blastospores (Taff et al. 2012; Rodrigues and Henriques 2017). C. tropicalis ATCC750 biofilm can be described as chains of cells
Table 1. MIC, MFC and MBEC values ( $\mathrm{mg} \mathrm{l}^{-1}$ ) for Csf and Mcf of $C$. glabrata, C. albicans, C. parapsilosis and C. tropicalis strains.

\begin{tabular}{|c|c|c|c|c|c|}
\hline \multirow{2}{*}{$\begin{array}{l}\text { Origin } \\
\text { Reference }\end{array}$} & \multicolumn{2}{|c|}{ Species/strain } & \multirow{2}{*}{ 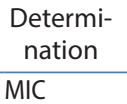 } & \multirow{2}{*}{$\begin{array}{c}\text { Caspo- } \\
\text { fungin } \\
0.064\end{array}$} & \multirow{2}{*}{$\begin{array}{c}\text { Micafungin } \\
0.032\end{array}$} \\
\hline & C. glabrata & ATCC2001 & & & \\
\hline & & & MFC & 0.10 & 0.20 \\
\hline & & & MBEC & $2.5-3$ & $16-17$ \\
\hline \multirow[t]{6}{*}{ Oral cavity } & & AE2 & MIC & $\leq 0.003$ & 0.002 \\
\hline & & & MFC & 0.003 & 0.06 \\
\hline & & & MBEC & $0.5-1$ & $7-8$ \\
\hline & & D1 & MIC & 0.003 & 0.002 \\
\hline & & & MFC & 0.003 & 0.06 \\
\hline & & & MBEC & $2.5-3$ & $3-3.5$ \\
\hline \multirow{6}{*}{$\begin{array}{l}\text { Urinary } \\
\text { tract }\end{array}$} & & 562123 & MIC & 0.001 & 0.01 \\
\hline & & & MFC & 0.001 & 0.10 \\
\hline & & & MBEC & $0.5-1$ & $16-17$ \\
\hline & & 513100 & MIC & 0.008 & 0.01 \\
\hline & & & MFC & 0.008 & 0.06 \\
\hline & & & MBEC & $2-2.5$ & 16 \\
\hline \multirow{6}{*}{$\begin{array}{c}\text { Vaginal } \\
\text { tract }\end{array}$} & & 534784 & MIC & $\leq 0.001$ & 0.002 \\
\hline & & & MFC & 0.05 & 0.06 \\
\hline & & & MBEC & $2.5-3$ & $5.5-6$ \\
\hline & & 585626 & MIC & 0.003 & 0.01 \\
\hline & & & MFC & 0.003 & 0.06 \\
\hline & & & MBEC & 2.5 & $5-5.5$ \\
\hline \multirow[t]{3}{*}{ Reference } & \multirow{3}{*}{\multicolumn{2}{|c|}{ C. albicans SC5314 }} & MIC & 0.016 & $\leq 0.016$ \\
\hline & & & MFC & 0.016 & 0.06 \\
\hline & & & MBEC & $2.5-3$ & 3.5 \\
\hline \multirow[t]{3}{*}{ Reference } & \multicolumn{2}{|c|}{ C. parapsilosis } & MIC & 0.016 & $>0.032$ \\
\hline & \multirow{2}{*}{\multicolumn{2}{|c|}{ ATCC22019 }} & MFC & 0.08 & 0.2 \\
\hline & & & MBEC & 2.5 & 16 \\
\hline \multirow[t]{3}{*}{ Reference } & \multirow{3}{*}{\multicolumn{2}{|c|}{ C. tropicalis ATCC750 }} & MIC & 0.008 & 0.002 \\
\hline & & & MFC & 0.016 & 0.06 \\
\hline & & & MBEC & 2.5 & 16 \\
\hline
\end{tabular}

Note: Bold indicates MBEC values.

Table 2. Percentage biomass reduction of C. glabrata, C. albicans, C. parapsilosis and C. tropicalis strains after caspofungin and micafungin contact.

\begin{tabular}{|c|c|c|c|}
\hline \multirow{2}{*}{ Species/strai } & & \multicolumn{2}{|c|}{$\%$ Biomass reduction ( $p$-value) } \\
\hline & & Caspofungin & Micafungin \\
\hline \multirow[t]{7}{*}{ C. glabrata } & ATCC2001 & $82.96\left(^{* *}\right)$ & $19.1\left(^{*}\right)$ \\
\hline & AE2 & $79.71\left(^{* * * *}\right)$ & $39.28{ }^{(* *)}$ \\
\hline & D1 & $69.71\left(^{*}\right)$ & 23.84 (ns) \\
\hline & 562123 & $85.16\left(^{* *}\right)$ & $70.47\left(^{* *}\right)$ \\
\hline & 513100 & 88.47 (****) & 66.59 (****) \\
\hline & 534784 & $73.38\left(^{*}\right)$ & 24.46 (ns) \\
\hline & 585626 & $\left.77.85{ }^{* *}\right)$ & $53.63(* *)$ \\
\hline \multicolumn{2}{|c|}{ C. albicans SC5314 } & $92.33\left(^{(* * *)}\right.$ & $82.13\left(^{* * *}\right)$ \\
\hline \multicolumn{2}{|c|}{ C. parapsilosis ATCC22019 } & $78.55\left(^{* * *}\right)$ & $38.86\left(^{* *}\right)$ \\
\hline \multicolumn{2}{|c|}{ C. tropicalis ATCC750 } & $\left.84.20{ }^{(* *}\right)$ & $53.49\left(^{*}\right)$ \\
\hline
\end{tabular}

Notes: ns, non-significant.

The concentrations applied in each species/strain were those determined by the MBECs. Overall ANOVA $p<0.05$ and post hoc Dunnett's comparison test: ${ }^{*} p<0.05 ;{ }^{* *} p<0.001 ;{ }^{* * *} p<0.0005 ;{ }^{* * *} p<0.0001$

with large amounts of extracellular material (Heffner and Franklin 1978; Rodrigues and Henriques 2017; Silva et al. 2017). After Csf and Mcf contact, the SEM images confirmed the CV results for all species/strains (Figure 1B). A biofilm reduction was observed in the presence of both drugs, but especially with Csf, and the biofilm cells presented a concave aspect and appear to have a reduction in the extracellular matrix. However, the extracellular matrix 
Control
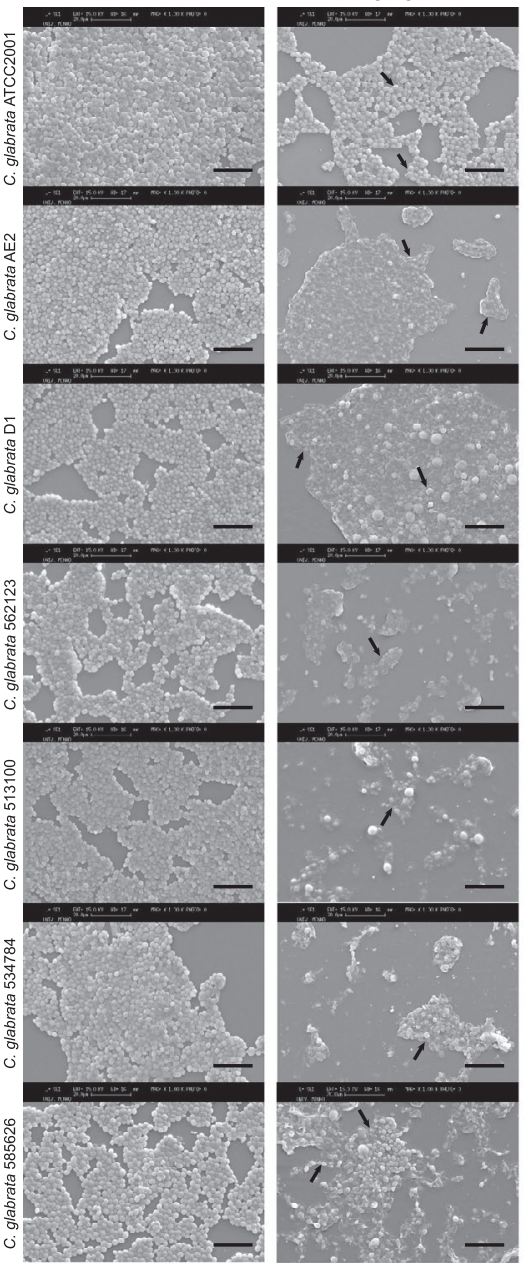

(B)
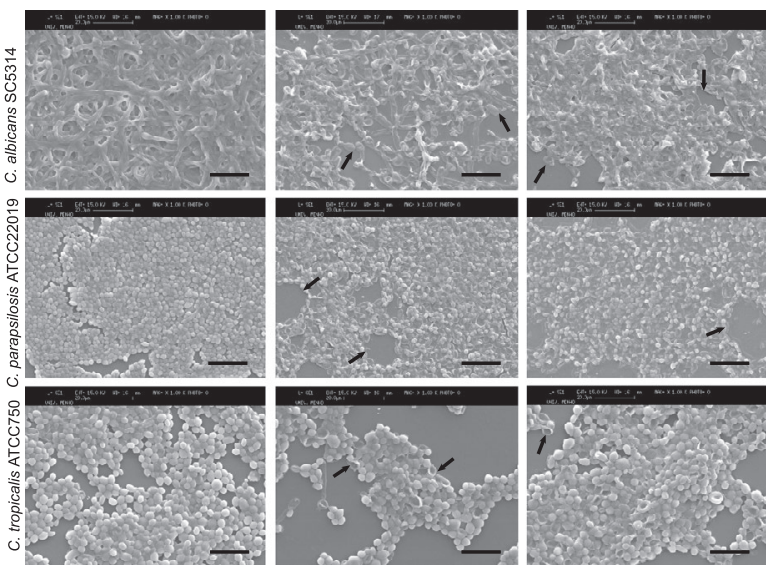

Figure 1. SEM observations of biofilms C. glabrata (A), C. albicans, C. parapsilosis and C. tropicalis (B) strains/species grown without drugs (control) and after caspofungin and micafungin contact. The concentrations applied to each species/strain were those determined by the MBECs. The arrows show disrupted biofilms and damaged Candida cells. Magnification: 1,000×. Scale bar $=20 \mu \mathrm{m}$.

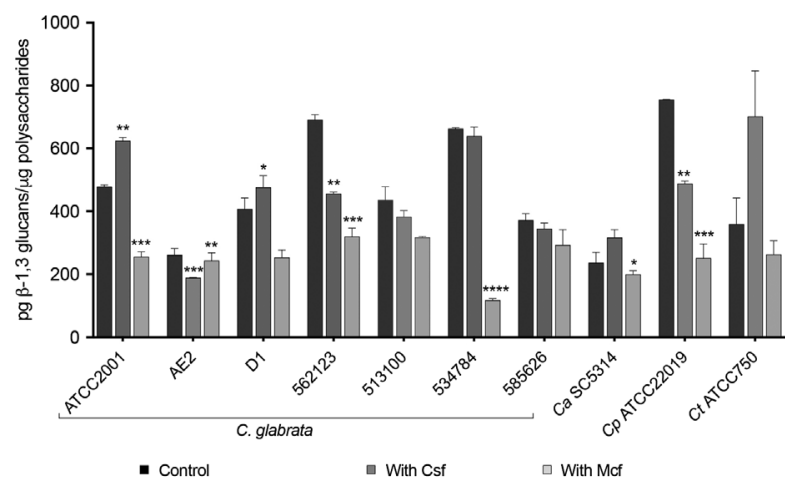

Figure 2. $\beta-1,3$ glucans concentration/polysaccharides content (pg $\mu^{-1}$ ) in 48-h biofilm matrices of C. glabrata, C. albicans (Ca), C. parapsilosis (Cp) and C. tropicalis (Ct). Overall ANOVA $p<0.05$ ANOVA and post hoc Tukey's comparisons test: ${ }^{*} p<0.05$; $\left.{ }^{* *} p<0.001 ;{ }^{* * *} p<0.0005 ;{ }^{* * *} p<0.0001\right)$.

of the different biofilms in the presence of the drugs seems to be different, which may be explained by variations in $\beta-1,3$ glucans, as was evaluated subsequently.

\section{Matrix composition after Csf and Mcf contact}

The results from the determination of the $\beta-1,3$ glucans concentration showed that, compared to the control groups and with some exceptions, the $\beta-1,3$ glucans generally tend to statistically decrease in the biofilm matrices of all Candida species, after contact with Csf and especially with Mcf (Figure 2). This reduction was not so prominent in C. glabrata, when compared to the other species (Figure 2).

\section{Discussion}

Systemic candidiasis is a growing problem in the hospitals worldwide (Cataldi et al. 2016; Rodrigues, Rodrigues et al. 2017), with high morbidity and mortality rates and elevated economic costs (Pfaller and Castanheira 2016; Silva et al. 2017). The present study evaluated the efficacy of two of the most used echinocandins - the first-line antifungal agents to treat systemic candidiasis (Pappas et al. 2015; McCarty and Pappas 2016) - of seven C. glabrata strains compared with the reference strains $C$. albicans, $C$. parapsilosis and C. tropicalis.

Considering MIC values of Mcf, EUCAST guidelines indicate breakpoints of $0.032 \mathrm{mg} \mathrm{l}^{-1}$ for C. glabrata, $0.016 \mathrm{mg} \mathrm{l}^{1}$ for C. albicans, $0.002-2 \mathrm{mg} \mathrm{l}^{-1}$ for C. parapsilosis. For $C$. tropicalis, the values are defined as 1-2 twofold dilution steps higher than for C. albicans and C. glabrata, but EUCAST attest that there is insufficient evidence to 
indicate whether the wild-type population can be considered susceptible to Mcf (EUCAST). For MIC Csf values, EUCAST breakpoints have not yet been established, due to significant inter-laboratory variation in the ranges for this drug (EUCAST). Possibly because of this, the authors had difficulty in defining these parameters. The occurrence of paradoxical growth of the isolates of Candida species, also enhanced the difficulties in MIC determination. The paradoxical effect is recognised as a robust mechanism of antifungal resistance. It is a resurgence of growth at drug concentrations above the MIC and connected to an increase in chitin biosynthesis whereby susceptible cells show growth at very high drug levels. Candida isolates display paradoxical effect more frequently when grown as biofilms compared to the planktonic form (Gow et al. 2007; Gil-Alonso et al. 2015, 2016; Scorzoni et al. 2017). The results, however, confirmed that all species/strains were Mcf susceptible (Table 1). EUCAST guidelines state that isolates that are susceptible to Mcf should be considered susceptible to Csf (EUCAST), hence all species/ strains were considered susceptible to this drug (Table 1). Although Mcf concentrations were, in most cases, higher than Csf concentrations, in general, the MIC, MFC and MBEC values were species/strain dependent. C. glabrata strains were revealed to have similar MIC, MFC and MBEC profiles to C. albicans SC5314, C. tropicalis ATCC750 and C. parapsilosis ATCC22019. Not surprisingly, the MBEC results evidenced the higher resistant profile of biofilm cells to antifungal agents than planktonic cells (Lewis et al. 2002; Al-Fattani and Douglas 2004; Ferrari et al. 2011; Grandesso et al. 2012; De Luca et al. 2012). In general, C. glabrata MIC values were shown to be closer, but slightly lower than those reported in the literature for some strains (Scott 2012; Naicker et al. 2016) and that all the strains were more susceptible to both echinocandins than C. glabrata ATCC2001 (EUCAST). Yet, and as supported by the reports, C. parapsilosis showed higher MIC values than the other Candida species (Arendrup et al. 2012; Arendrup and Pfaller 2012; Arendrup and Perlin 2014; Pham et al. 2014; Gil-Alonso et al. 2015). It is known that some Candida species have naturally occurring polymorphisms in their FKS genes, which strongly reduce their susceptibility to echinocandin drugs (Arendrup et al. 2012; Perlin 2015a). Moreover, the C. parapsilosis family (C. orthopsilosis and C. metapsilosis) and Candida guilliermondii, normally also have higher MIC values compared to other susceptible Candida species (Pfaller et al. 2008, 2010; Tortorano et al. 2013; Perlin 2015b).

The results of CV staining indicated, altogether, an effective reduction in the biomass of the species/strains after echinocandin exposure (Table 2). Yet, Csf showed a higher biomass reduction capacity than Mcf, with a minimal reduction of $70 \%$ of the biofilms. Similar results have been indicated previously in studies with catheters (Falcone et al. 2009; Dutronc et al. 2010; Williams and Ramage 2015). Mcf did not reveal a complete eradication of the biofilm, as it has been reported for Csf (Cateau et al. 2008, 2011). This conclusion was particularly noticed in C. glabrata (four of the seven strains had the lowest Mcf biomass percentage reduction), which can be related to the usual antifungal resistance profile of this species (Jabra-rizk et al. 2004; Farmakiotis et al. 2014; Perlin et al. 2015; Silva et al. 2017). Interestingly, the efficacy of the biomass reduction by Csf was not always related to the use of the highest drug concentration. In some cases, a high Csf concentration would lead to a low drug activity and, thus, to a lower biomass reduction, revealing a probable paradoxical effect (Wiederhold 2009; Perlin 2014; GilAlonso et al. 2015; Scorzoni et al. 2017). By applying an adequate concentration for the strain (sometimes a lower drug dose), this effect was not detected, and the biomass was effectively reduced.

In order to evaluate the extent of the antifungal effect of Csf and Mcf on the biofilms, SEM images were taken (Figure 1A and B). The controls revealed that all Candida species had a good capacity for biofilm production. After Csf and Mcf contact (Figure 1B), and particularly with Csf, a strong biofilm reduction, was observed (arrows in the Figure 1). The biofilm cells seemed to be disrupted and presented a concave aspect (arrows in Figure 1), endorsing the $\mathrm{CV}$ results (Table 2). This disruption and change in the cell configuration is expected to result from the mechanism of action of the echinocandins (non-competitive inhibition of $\beta$-1,3-glucan synthesis) (Rodrigues, Rodrigues et al. 2017; Scorzoni et al. 2017), which affects the cell wall and the matrix composition. Fungal cell wall polysaccharides are significant constituents of the biofilm matrix of Candida species (Chandra et al. 2001; Kuhn et al. 2002). The biofilm matrix composition of C. glabrata, C. albicans, C. parapsilosis and C. tropicalis strains with and without Csf and Mcf contact were evaluated in terms of $\beta-1,3$ glucan content (Figure 2). To the authors' knowledge, this is the first report describing such content of the biofilm matrices of Candida species in contact with these two echinocandins. The $\beta-1,3$ glucans are a group of specific polysaccharides from the cell walls of Candida species that are also recognised as major constituents of the biofilm matrices of this genus (Chandra et al. 2001; Kuhn et al. 2002). Regarding the controls (non-treated biofilms), C. albicans SC5314 was the species that had a lower quantify of $\beta-1,3$ glucans in the matrix and $C$. parapsilosis ATCC22019, C. glabrata 534784 and C. glabrata 562123 were revealed to have the highest content of this glucan, which could be one of the probable mechanisms for the resistant profile of the biofilms (Figure 2). After adding Csf and Mcf to the pre-formed biofilms, the results 
from the determination of the $\beta-1,3$ glucan concentrations (Figure 2) demonstrated that these compounds are, in general, statistically significantly likely to reduce in the biofilm matrices of C. glabrata, and in the other Candida species. Exceptions were noted only after the addition of Csf to C. glabrata ATCC2001, C. glabrata D1 and C. tropicalis ATCC750. It is also important to note that the initial concentration of $\beta-1,3$ glucans was very dependent on the strain and that, excepting C. glabrata 534784, the variations between the strains and the Mcf groups were less pronounced than those detected between the strains and Csf groups.

Another source of variability in the drug response might be the chemical differences between the two echinocandin molecules. Both Csf and Mcf have a cyclic peptide structure with a $\mathrm{N}$-aryl group but with different patterns of hydroxylations and amino groups (R2 to R4). The $\mathrm{N}$-aryl side chain (position R1) plays a critical role in the potency and toxicity and is the main point for chemical modification of the echinocandin analogues (Debono and Gordee 1994; Wiederhold and Lewis 2003). Csf and Mcf have also variations in R2, R3 and R4 positions: Csf is more hydroxylated and has more amino groups, while Mcf has more aryl groups. It is documented that the replacement of the linoleoyl side chain with aryl side chains of low lipophilicity, nonlinear configuration or chains switched with highly polar groups end in loss of antifungal activity, which suggests that planar, non-polar substitutions are critical for the antifungal activity (Debono and Gordee 1994; Wiederhold and Lewis 2003). These modifications were performed on the Mcf molecule and are also a probable explanation for the differences found, in this work, for the drug activity in the species and strains studied (higher MBEC values and matrix variations, when compared to Csf).

This report shows a general parallelism in the efficacy of the Csf and Mcf susceptibilities of C. glabrata in comparison to C. albicans, C. parapsilosis and C. tropicalis with respect to planktonic cells (MIC/MFC). It seems plausible to say that the external alterations in the matrix composition of the Candida strains and the chemical alterations in the Csf and Mcf molecules can partially explain and determine the effectiveness response to these two drugs of biofilm infections of Candida species and, particularly, C. glabrata.

\section{Acknowledgements}

The authors would like to acknowledge $\mathrm{MSD}^{\circ}$ and Astellas for the kind donation of Caspofungin and Micafungin, respectively.

\section{Disclosure statement}

All the authors declare there is no financial/personal interest or belief that could affect their objectivity.

\section{Funding}

This study was supported by the Portuguese Foundation for Science and Technology (FCT) under the scope of the strategic funding of UID/BIO/04469/2013 unit and COMPETE 2020 [POCI-01-0145-FEDER-006684] and BioTecNorte operation [NORTE-01-0145-FEDER-000004] funded by the European Regional Development Fund under the scope of Norte2020 Programa Operacional Regional do Norte, Célia F. Rodrigues' [SFRH/BD/93078/2013] PhD grant and M. Elisa Rodrigues [SFRH/BPD/95401/2013] post-doctoral grant.

\section{ORCID}

Célia F. Rodrigues iD http://orcid.org/0000-0001-8633-2230 Maria Elisa Rodrigues (iD http://orcid.org/0000-0001-88239494

Mariana Henriques (D) http://orcid.org/0000-0003-0317-4877

\section{References}

Al-Fattani M, Douglas LJ. 2004. Penetration of Candida biofilms by antifungal agents. Antimicrob Agents Chemother. 48:3291-3297. doi:10.1128/AAC.48.9.3291-3297.2004.

Arendrup MC, Arikan S, Barchiesi F, Bille J, Dannaoui E, Denning DW, Donnelly JP, Fegeler W, Moore C, Richardson M, et al. 2008. EUCAST Technical Note on the method for the determination of broth dilution minimum inhibitory concentrations of antifungal agents for conidia - forming moulds. ESCMID Tech Notes. 14:982-984.

Arendrup M, Perlin D, Jensen R, Howard S, Goodwin J, Hopec W. 2012. Differential in vivo activities of anidulafungin, caspofungin, and micafungin against Candida glabrata isolates with and without FSK resistance mutations. Antim Agents Chemoter. 56:2435-2442.

Arendrup MC, Perlin DS. 2014. Echinocandin resistance: an emerging clinical problem? Curr Opin Infect Dis. 27:484-492.

Arendrup MC, Pfaller Ma. 2012. Caspofungin Etest susceptibility testing of Candida species: risk of misclassification of susceptible isolates of C. glabrata and C. krusei when adopting the revised CLSI caspofungin breakpoints. Antimicrob Agents Chemother. 56:3965-3968. doi:10.1128/AAC.00355-12.

Barchiesi F, Spreghini E, Tomassetti S, Arzeni D, Giannini D, Scalise G. 2005. Comparison of the fungicidal activities of caspofungin and amphotericin B against Candida glabrata. Antimicrob Agents Chemother. 49:4989-4992. doi:10.1128/ AAC.49.12.4989-4992.2005.

Cataldi V, Di Campli E, Fazii P, Traini T, Cellini L, Di Giulio M. 2016. Candida species isolated from different body sites and their antifungal susceptibility pattern: cross-analysis of Candida albicans and Candida glabrata biofilms. Med Mycol:myw126. doi:10.1093/mmy/myw126.

Cateau E, Berjeaud J-M, Imbert C. 2011. Possible role of azole and echinocandin lock solutions in the control of Candida biofilms associated with silicone. Int J Antimicrob Agents. 37:380-384. doi:10.1016/j.ijantimicag.2010.12.016.

Cateau E, Rodier M-H, Imbert C. 2008. In vitro efficacies of caspofungin or micafungin catheter lock solutions on Candida albicans biofilm growth. J Antimicrob Chemother. 62:153-155. doi:10.1093/jac/dkn160. 
Chandra J, Kuhn D, Mukherjee P, Hoyer L, McCormick T, Ghannoum M. 2001. Biofilm formation by the fungal pathogen Candida albicans: development, architecture, and drug resistance. J Bacteriol. 183:5385-5394. doi:10.1128/ JB.183.18.5385-5394.2001.

Chang CC, Slavin MA, Chen SCAC-A. 2017. New developments and directions in the clinical application of the echinocandins. Arch Toxicol. 91:1613-1621. doi:10.1007/ s00204-016-1916-3.

Chapman B, Slavin M, Marriott D, Halliday C, Kidd SE, Arthur I, Bak N, Heath CH, Kennedy K, Morrissey CO, et al. 2017. Changing epidemiology of candidaemia in Australia. J Antimicrob Chemother. 72:1103-1108.

Costerton JW, Lewandowski Z, Caldwell DE, Korber DR, Lappin-Scott HM. 1995. Microbial biofilms. Annu Rev Microbiol. 49:711-745. doi:10.1146/annurev. mi.49.100195.003431.

De Luca C, Guglielminetti M, Ferrario A, Calabrò M, Casari E. 2012. Candidemia: species involved, virulence factors and antimycotic susceptibility. New Microbiol. 35:459-468.

Debono M, Gordee RSS. 1994. Antibiotics that inhibit fungal cell wall development. Annu Rev Microbiol. 48:471-497. doi:10.1146/annurev.mi.48.100194.002351.

Dominguez E, Zarnowski R, Sanchez H, Covelli AS, Westler WM, Azadi P, Nett J, Mitchell AP, Andes DR. 2018. Conservation and divergence in the Candida species biofilm matrix mannan-glucan complex structure, function, and genetic control. MBio. 9:e00451-18.

Donlan R, Costerton J. 2002. Biofilms: survival mechanisms of clinically relevant microorganism. Clin Microbiol Rev. 15:167-193. doi:10.1128/CMR.15.2.167-193.2002.

Douglas LJ. 2003. Candida biofilms and their role in infection. Trends Microbiol. 11:30-36. doi:10.1016/S0966842X(02)00002-1.

DuBois M, Gilles K, Hamilton J, Rebers P, Smith F. 1956. Colorimetric method for determination of sugars and related substances. Anal Chem. 28:350-356. doi:10.1021/ac60111a017.

Dutronc H, Dauchy FA, Cazanave C, Rougie C, Lafarie-Castet S, Couprie B, Fabre T, Dupon M. 2010. Candida prosthetic infections: case series and literature review. Scand J Infect Dis. 42:890-895. doi:10.3109/00365548.2010.498023.

Emri T, Majoros L, Tóth V, Pócsi I. 2013. Echinocandins: production and applications. Appl Microbiol Biotechnol. 97:3267-3284. doi:10.1007/s00253-013-4761-9.

EUCAST. [date unknown]. Breakpoint tables for interpretation of MICs, Version 8.1, valid from 2017-0301. http://www.eucast.org/fileadmin/src/media/PDFs/ EUCAST_files/AFST/Clinical_breakpoints/Antifungal_ breakpoints_v_8.1_March_2017.pdf

Falcone M, Barzaghi N, Carosi G, Grossi P, Minoli L, Ravasio V, Rizzi M, Suter F, Utili R, Viscoli C, et al. 2009. Candida infective endocarditis. Medicine (Baltimore). 88:160-168. doi:10.1097/MD.0b013e3181a693f8.

Farmakiotis D, Tarrand JJJ, Kontoyiannis DPDP. 2014. Drugresistance Candida glabrata infection in cancer patients. Emerg Infect Dis. 20:11-26.

Ferrari S, Sanguinetti M, De Bernardis F, Torelli R, Posteraro B, Vandeputte P, Sanglard D. 2011. Loss of mitochondrial functions associated with azole resistance in Candida glabrata results in enhanced virulence in mice. Antimicrob Agents Chemother. 55:1852-1860. doi:10.1128/AAC.01271-10.
Fonseca E, Silva S, Rodrigues C, Alves C, Azeredo J, Henriques M. 2014. Effects of fluconazole on Candida glabrata biofilms and its relationship with $\mathrm{ABC}$ transporter gene expression. Biofouling. 30:447-457. doi:10.1080/08927014.2014.886108.

Garcia-Cuesta C, Sarrion-Pérez M-G, Bagán JV, Sarrion-Perez MG, Bagan JV. 2014. Current treatment of oral candidiasis: a literature review. J Clin Exp Dent. 6:e576-e582. doi:10.4317/ jced.51798.

Gil-Alonso S, Jauregizar N, Cantón E, Eraso E, Quindós G. 2015. In Vitro fungicidal activities of anidulafungin, caspofungin, and micafungin against Candida glabrata, Candida bracarensis, and Candida nivariensis evaluated by time-kill studies. Antimicrob Agents Chemother. 59:36153618. doi:10.1128/AAC.04474-14.

Gil-Alonso S, Jauregizar N, Ortega I, Eraso E, Suárez E, Quindós G. 2016. In vitro pharmacodynamic modelling of anidulafungin against Candida spp. Int J Antimicrob Agents. 47:178-183. doi:10.1016/j.ijantimicag.2015.12.011.

Gow NAR, Netea MG, Munro CA, Ferwerda G, Bates S, MoraMontes HM, Walker L, Jansen T, Jacobs L, Tsoni V, et al. 2007. Immune recognition of Candida albicans beta-glucan by dectin-1. J Infect Dis. 196:1565-1571. doi:10.1086/525005.

Grandesso S, Sapino B, Mazzuccato S, Solinas M, Bedin M, D’Angelo M, Gion M. 2012. Study on in vitro susceptibility of Candida spp. isolated from blood culture. Infect Med. 20:25-30.

Hawser SP, Douglas LJ. 1995. Resistance of Candida albicans biofilms to antifungal agents in vitro. Antimicrob Agents Chemother. 39:2128-2131. doi:10.1128/AAC.39.9.2128.

Heffner D, Franklin W. 1978. Endocarditis caused by Torulopsis glabrata. Am J Clin Pathol. 70:420-423. doi:10.1093/ ajcp/70.3.420.

Jabra-rizk MA, Falker WA, Meiller TF. 2004. Fungal biofilms and drug resistance. Emerg Infect. 10:19.

Kohno S, Izumikawa K, Yoshida M, Takesue Y, Oka S, Kamei K, Miyazaki Y, Yoshinari T, Kartsonis NA, Niki Y. 2013. A double-blind comparative study of the safety and efficacy of caspofungin versus micafungin in the treatment of candidiasis and aspergillosis. Eur J Clin Microbiol Infect Dis. 32:387-397. doi:10.1007/s10096-012-1754-z.

Kuhn D, Chandra J, Mukherjee P, Ghannoum M. 2002. Comparison of biofilms formed by Candida albicans and Candida parapsilosis on bioprosthetic surfaces. Infect Immun. 70:878-888. doi:10.1128/IAI.70.2.878-888.2002.

Lewis R, Kontoyiannis D, Darouiche R, Raad I, Prince R. 2002. Antifungal activity of amphotericin B, fluconazole, and voriconazole in an in vitro model of Candida catheter-related bloodstream infection. Antimicrob Agents Chemother. 46:3499-3505. doi:10.1128/AAC.46.11.3499-3505.2002.

Li L, Redding S, Dongari B. 2007. Candida glabrata, an Emerging Oral Opportunistic Pathogen. J Dent Res. 86:204215. doi:10.1177/154405910708600304.

McCall A, Edgerton M. 2017. Real-time approach to flow cell imaging of Candida albicans biofilm development. J Fungi. 3:13. doi:10.3390/jof3010013.

McCarty TP, Pappas PG. 2016. Invasive candidiasis. Infect Dis Clin North Am. 30:103-124.

Naicker SD, Magobo RE, Zulu TG, Maphanga TG, Luthuli N, Lowman W, Govender NP. 2016. Two echinocandin-resistant Candida glabrata FKS mutants from South Africa. Med Mycol Case Rep. 11:24-26. doi:10.1016/j.mmcr.2016.03.004. 
Pappas PG. 2006. Invasive candidiasis. Infect Dis Clin North Am. 20:485-506. doi:10.1016/j.idc.2006.07.004.

Pappas PG, Kauffman CA, Andes DR, Clancy CJ, Marr KA, Ostrosky-Zeichner L, Reboli AC, Schuster MG, Vazquez JA, Walsh TJ, et al. 2015. Clinical practice guideline for the management of candidiasis: 2016 update by the Infectious Diseases Society of America. Clin Infect Dis. 62:e1-e50.

Pappas PG, Rotstein CMF, Betts RF, Nucci M, Talwar D, De Waele JJ, Vazquez JA, Dupont BF, Horn DL, Ostrosky-Zeichner L, et al. 2007. Micafungin versus caspofungin for treatment of candidemia and other forms of invasive candidiasis. Clin Infect Dis. 45:883-893. doi:10.1086/520980.

Perlin DS. 2007. Resistance to echinocandin- class antifungal drugs. Drug Resist Updat. 10:121-130. doi:10.1016/j. drup.2007.04.002.

Perlin DS. 2014. Echinocandin resistance, susceptibility testing and prophylaxis: implications for patient management. Drugs. 74:1573-1585. doi:10.1007/s40265-014-0286-5.

Perlin DS. 2015a. Mechanisms of echinocandin antifungal drug resistance. Ann N Y Acad Sci:1-11. doi:10.1111/ nyas.2015.1354.issue-1.

Perlin DS. 2015b. Echinocandin resistance in Candida. Clin Infect Dis. 61:S612-S617. doi:10.1093/cid/civ791.

Perlin DS, Shor E, Zhao Y. 2015. Update on antifungal drug resistance. Curr Clin Microbiol Reports. 2:84-95. doi:10.1007/s40588-015-0015-1.

Perlin DS, Teppler H, Donowitz GR, Maertens JA, Baden LR, Milne S, Brown AJ, Gow NA. 2007. Resistance to echinocandin-class antifungal drugs. Drug Resist Updat. 10:121-130. doi:10.1016/j.drup.2007.04.002.

Pfaller MA, Boyken L, Hollis RJ, Kroeger J, Messer SA, Tendolkar S, Diekema DJ. 2008. In Vitro susceptibility of invasive isolates of Candida spp. to anidulafungin, caspofungin, and micafungin: six years of global surveillance. J Clin Microbiol. 46:150-156. doi:10.1128/JCM.01901-07.

Pfaller MA, Boyken L, Hollis RJ, Kroeger J, Messer SA, Tendolkar S, Jones RN, Turnidge J, Diekema DJ. 2010. Wildtype MIC distributions and epidemiological cutoff values for the echinocandins and Candida spp. J Clin Microbiol. 48:52-56. doi:10.1128/JCM.01590-09.

Pfaller MA, Castanheira M. 2016. Nosocomial candidiasis: antifungal stewardship and the importance of rapid diagnosis. Med Mycol. 54:1-22.

Pham CD, Iqbal N, Bolden CB, Kuykendall RJ, Harrison LH, Farley MM, Schaffner W, Beldavs ZG, Chiller TM, Park BJ, et al. 2014. Role of FKS mutations in Candida glabrata: MIC values, echinocandin resistance, and multidrug resistance. Antimicrob Agents Chemother. 58:4690-4696. doi:10.1128/ AAC.03255-14.

Pierce C, Vila T, Romo J, Montelongo-Jauregui D, Wall G, Ramasubramanian A, Lopez-Ribot J. 2017. The Candida albicans biofilm matrix: composition, structure and function. J Fungi. 3:14. doi:10.3390/jof3010014.

Ramage G, Rajendran R, Sherry L, Williams C. 2012. Fungal biofilm resistance. Int J Microbiol. 2012:528521.

Rodrigues CF, Gonçalves B, Rodrigues ME, Silva S, Azeredo J, Henriques M. 2017. The effectiveness of voriconazole in therapy of Candida glabrata's biofilms oral infections and Its Influence on the matrix composition and gene expression. Mycopathologia [Internet] [accessed 2017 Jun 21]; 182:653664. http://www.ncbi.nlm.nih.gov/pubmed/28439794
Rodrigues CF, Henriques M. 2017. Liposomal and deoxycholate amphotericin B formulations: effectiveness against biofilm infections of Candida spp. Pathogens. 6:13.

Rodrigues CF, Silva S, Henriques M. 2014. Candida glabrata: a review of its features and resistance. Eur J Clin Microbiol Infect Dis. 33:673-688. doi:10.1007/s10096-013-2009-3.

Rodrigues CF, Rodrigues ME, Silva S, Henriques M. 2017. Candida glabrata biofilms: how far have we come? J Fungi. 3:11. doi:10.3390/jof3010011.

Scorzoni L, de Paula e Silva ACA, Marcos CM, Assato PA, de Melo WCMA, de Oliveira HC, Costa-Orlandi CB, MendesGiannini MJS, Fusco-Almeida AM. 2017. Antifungal therapy: new advances in the understanding and treatment of mycosis. Front Microbiol. 8:1-23.

Scott LJ. 2012. Micafungin: a review of its use in the prophylaxis and treatment of invasive Candida infections. Drugs. 72:2141-2165. doi:10.2165/11209970-000000000-00000.

Silva S, Rodrigues CF, Araújo D, Rodrigues M, Henriques M. 2017. Candida species biofilms' antifungal resistance. J Fungi. 3:8. doi:10.3390/jof3010008.

Spreghini E, Orlando F, Sanguinetti M, Posteraro B, Giannini D, Manso E, Barchiesi F. 2012. Comparative effects of micafungin, caspofungin, and anidulafungin against a difficult-to-treat fungal opportunistic pathogen, Candida glabrata. Antimicrob Agents Chemother. 56:1215-1222. doi:10.1128/AAC.05872-11.

Stevens DA, Ichinomiya M, Koshi Y, Horiuchi H. 2006. Escape of Candida from caspofungin inhibition at concentrations above the MIC (paradoxical effect) accomplished by increased cell wall chitin; evidence for beta-1,6-glucan synthesis inhibition by caspofungin. Antimicrob Agents Chemother. 50:3160-3161. doi:10.1128/AAC.00563-06.

Taff H, Nett J, Andes D. 2012. Comparative analysis of Candida biofilm quantitation assays. Med Mycol. 50:214-218. doi:10. 3109/13693786.2011.580016.

Taylor PR, Tsoni SV, Willment JA, Dennehy KM, Rosas M, Findon H, Haynes K, Steele C, Botto M, Gordon S, Brown GD. 2007. Dectin-1 is required for ?-glucan recognition and control of fungal infection. Nat Immunol. 8:31-38. doi:10.1038/ni1408.

Tortorano AM, Prigitano A, Lazzarini C, Passera M, Deiana ML, Cavinato S, De Luca C, Grancini A, Lo Cascio G, Ossi C, et al. 2013. A 1-year prospective survey of candidemia in Italy and changing epidemiology over one decade. Infection. 41:655-662. doi:10.1007/s15010-013-0455-6.

Tragiannidis A, Dokos C, Lehrnbecher T, Groll AH. 2012. Antifungal chemoprophylaxis in children and adolescents with haematological malignancies and following allogeneic haematopoietic stem cell transplantation. Drugs. 72:685704. doi:10.2165/11599810-000000000-00000.

Uppuluri P, Chaturvedi A, Srinivasan G, Banerjee M, Ramasubramaniam A, et al. 2010. Dispersion as an important step in the Candida albicans biofilm developmental cycle. PLoS Pathog. 6:e1000828. doi:10.1371/journal. ppat.1000828.

Viscoli C, Bassetti M, Castagnola E, Cesaro S, Menichetti F, Ratto S, Tascini C, Giacobbe DR. 2014. Micafungin for the treatment of proven and suspected invasive candidiasis in children and adults: findings from a multicenter prospective observational study. BMC Infect Dis. 14:e24198. doi:10.1186/ s12879-014-0725-7. 
Wiederhold NP. 2009. Paradoxical echinocandin activity: a limited in vitro phenomenon? Med Mycol. 47(Suppl 1):S369-S375. doi:10.1080/13693780802428542.

Wiederhold NP, Lewis RE. 2003. The echinocandin antifungals: an overview of the pharmacology, spectrum and clinical efficacy. Expert Opin Investig Drugs. 12:1313-1333. doi:10.1517/13543784.12.8.1313.

Wiederhold NP, Najvar LK, Bocanegra R, Molina D, Olivo $\mathrm{M}$, Graybill JR. 2007. In vivo efficacy of anidulafungin and caspofungin against Candida glabrata and association with in vitro potency in the presence of sera. Antimicrob Agents Chemother. 51:1616-1620. doi:10.1128/AAC.00105-07.

Williams C, Ramage G. 2015. Fungal biofilms in human disease. Adv Exp Med Biol. 831: 11-27. doi:10.1007/978-3319-09782-4.

Williams DW, Wilson MJ, Lewis MAO, Potts AJC. 1995. Identification of Candida species by PCR and restriction fragment length polymorphism analysis of intergenic spacer regions of ribosomal DNA. J Clin Microbiol. 33:2476-2479. 